\title{
The expression of Dicer and Drosha in matched normal tissues, tumours and lymph node metastases in triple negative breast cancer
}

\author{
Kelly A Avery-Kiejda ${ }^{1,2^{*}}$, Stephen G Braye ${ }^{3}$, John F Forbes ${ }^{4,5}$ and Rodney J Scott ${ }^{1,2,3}$
}

\begin{abstract}
Background: Breast cancer is the most common malignancy in women world-wide. Triple negative breast cancer (TNBC) is a highly aggressive subtype that lacks expression of hormone receptors for estrogen, progesterone and human epidermal growth factor 2; and is associated with a high propensity for metastatic spread. Several studies have identified critical roles for microRNAs in breast cancer, but the role of two critical enzymes involved in microRNA biogenesis, Dicer and Drosha, is not well understood, particularly with respect to metastatic progression in this subtype.

Methods: We examined the expression of Dicer and Drosha in a series of invasive 35 TNBCs with matched normal adjacent tissues $(n=18)$ and lymph node metastases $(n=15)$ using semi-quantitative real time RT-PCR. The relationship of their expression with clinical features including age at diagnosis, lymph node positivity and tumour size was analysed.

Results: We report that Dicer was significantly decreased while Drosha was significantly increased in tumours when compared to normal adjacent tissues. While there was no difference in Drosha expression in lymph node metastases when compared to the primary tumour, Dicer was significantly increased. There was no correlation between the expression of either Dicer or Drosha to age at diagnosis, lymph node positivity and tumour size.

Conclusions: In conclusion, Dicer and Drosha are dysregulated in TNBC and matched lymph node metastases however, the clinical relevance of this is still not known. The altered expression of Dicer and Drosha may serve as markers for disrupted miRNA biogenesis in TNBC.
\end{abstract}

Keywords: Dicer, Drosha, Breast cancer, Metastasis, Triple negative

\section{Background}

Breast cancer is the most common malignancy that develops in women worldwide, responsible for the highest cancer-associated death rates [1]. Triple negative breast cancer (TNBC) represents an important clinical subtype, characterised by an absence of estrogen receptor (ER), progesterone receptor (PR) and human epidermal growth factor receptor 2 (HER2) and which therefore lack common targets used for anti-hormone therapies [2,3]. Although TNBCs comprise only a small percentage of all

\footnotetext{
* Correspondence: Kelly.Kiejda@newcastle.edu.au

${ }^{1}$ Centre for Information-Based Medicine, Hunter Medical Research Institute, John Hunter Hospital, New Lambton Heights, NSW 2305, Australia

${ }^{2}$ School of Biomedical Sciences and Pharmacy, Faculty of Health, University of Newcastle, Callaghan, NSW 2308, Australia

Full list of author information is available at the end of the article
}

breast cancers diagnosed (10-24\%), patients are of younger age, tend to develop tumours of larger size, and have an increased likelihood of distant metastasis and death within 5 years of diagnosis [2,3]. Thus, TNBCs represent a major problem for which targeted therapies are currently not available.

microRNAs (miRNAs) are a class of small ( 22 nucleotides) non-coding RNAs that control gene expression by targeting mRNAs and triggering either translational repression or RNA degradation [4]. Several studies have identified critical roles for miRNAs in breast cancer diagnosis and prognosis [5-10]. Two enzymes, Drosha and Dicer, are pivotal in the processing of pri-miRNA into mature double stranded miRNA fragments [4]. Drosha is a nuclear enzyme that cleaves primary miRNA transcripts

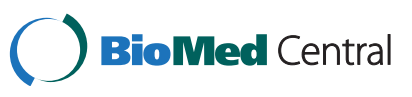


(pri-miRNA) into short ( $\sim 70$ nucleotides) double-stranded RNA precursors that contain a 3' overhang, known as premiRNA [11]. The pre-miRNAs are then exported to the cytoplasm where they are cleaved by Dicer into mature double-stranded miRNA fragments of approximately 22 nucleotides in length [11]. Numerous studies have investigated the role of Drosha and Dicer in a variety of cancers including breast, lung, ovarian, colorectal and esophageal cancer [12-23]. In breast cancer, both Dicer and Drosha expression have been reported to be reduced when compared to normal adjacent tissue [18-23]. Reduced expression of Dicer has been associated with high grade, shorter metastasis-free survival and with the TNBC subtype [19,21-23]. A reduction in the expression of Drosha in breast cancer has been reported to be associated with high grade and shorter disease free survival [18,21]. However, there have been no studies regarding the association of Dicer or Drosha with clinical features or their role in breast cancer progression in TNBC, a highly aggressive breast cancer subtype with a propensity for metastatic spread.

In this study we examined the expression of Dicer and Drosha in a series of 35 TNBCs with matched normal adjacent tissues $(\mathrm{n}=18)$ and lymph node $(\mathrm{LN})$ metastases $(n=15)$ using semi-quantitative real time RT-PCR. The correlation of their expression with clinical features including age at diagnosis, $\mathrm{LN}$ positivity and tumour size was also examined.

\section{Methods}

\section{Study cohort}

Thirty-five formalin-fixed paraffin-embedded (FFPE) invasive ductal carcinomas (IDCs) were obtained from Hunter Area Pathology Service, John Hunter Hospital, Newcastle, Australia. All patients were diagnosed with grade 3 IDC between the years of 2004-2009, and were negative for ER, PR and HER2 as assessed through routine diagnostic pathology. The demographic details of this cohort have previously been published [24] Areas of tissue representing histologically normal adjacent breast tissue (NAT, where available, $\mathrm{n}=18$ ), IDC and LN metastases $(n=15)$ were identified and confirmed by a pathologist. Micrometastases $(<2 \mathrm{~mm})$ were not used. A $1.5 \mathrm{~mm}$ punch biopsy was used to punch cores from the paraffin blocks using haemotoxylin and eosin stained sections of the same sample for guidance. Tumour volume in the core biopsy was $>70 \%$ of the total. This study complies with the Helsinki Declaration with ethical approval from the Hunter New England Human Research Ethics Committee (Approval number: 09/05/20/5.02). In accordance with the National Statement on Ethical Conduct in Research Involving Humans, a waiver of consent was granted for this study.

\section{Extraction of RNA}

Total RNA was extracted using the miRNeasy FFPE kit (Qiagen, Doncaster, VIC, Australia). RNA was quantified using the Quant-it RiboGreen RNA Assay kit (Invitrogen, Mulgrave, VIC, Australia) and purity assessed by $\mathrm{A}_{260 / \mathrm{A} 280}$ and $\mathrm{A}_{260 / 230}$ ratios (>1.8) using the Nanodrop. The RNA integrity of selected samples was analysed using the 2100 Bioanalyser and the RNA 6000 Nano kit (Agilent Technologies, Mulgrave, VIC, Australia).

\section{Semi-quantitative real-time PCR}

Total RNA (250 ng) was reverse transcribed using the High Capacity cDNA Reverse Transcription Kit (Life Technologies, Mulgrave, VIC, Australia) which utilises random hexamers in the reverse transcription reaction. Real-time PCR analysis was performed in triplicate using TaqMan $^{\bullet}$ Universal PCR mix (Life Technologies) according to the manufacturers' instructions, with results quantified on a 7500 real-time PCR system (Life Technologies) as described previously [25]. The expression of Dicer (Hs00998588_g1), Drosha (Hs00203008_m1) and B2Microglobulin (Hs99999907_m1) were quantified using Taqman Gene Expression Assays (Life Technologies). The relative expression of the Dicer and Drosha were normalised to $\beta 2$-Microglobulin $(\Delta \mathrm{Ct})$ and expressed as the fold change as described previously [25]. We have verified that $\beta 2$-Microglobulin is equally expressed among the different tissues analysed in this study (NAT, IDC, LN) (Additional file 1: Table S1 and Additional file 1: Figure S1).

\section{Statistical analysis}

The normality of the data distribution was tested using a D'Agostino and Pearson Omnibus test. The values were found not to have been sampled from a Gaussian distribution and thus, non-parametric statistical tests were used to compare the data. A two-tailed Mann-Whitney U test was used to determine if there was a statistically significant difference in the expression of Dicer and Drosha between any two subgroups. The Wilcoxon matched-pairs signed rank test was used to determine if there was a statistically significant difference in the expression of Dicer and Drosha between matched pairs. The Kruskal-Wallis rank test followed by a Dunn's Multiple Correction test was used to determine the statistical significance of Dicer and Drosha expression between multiple ( $>2)$ subgroups. Analysis of the correlation between Dicer and Drosha expression and clinical parameters was performed using Spearman's correlation test. All analysis was performed using GraphPad Prism (version 5.04, GraphPad software Inc., La Jolla, CA, USA).

\section{Results}

Drosha is more highly expressed than Dicer in TNBC

The expression of Dicer and Drosha was quantitated in all 35 TNBCs by real time RT-PCR. The relative mRNA 

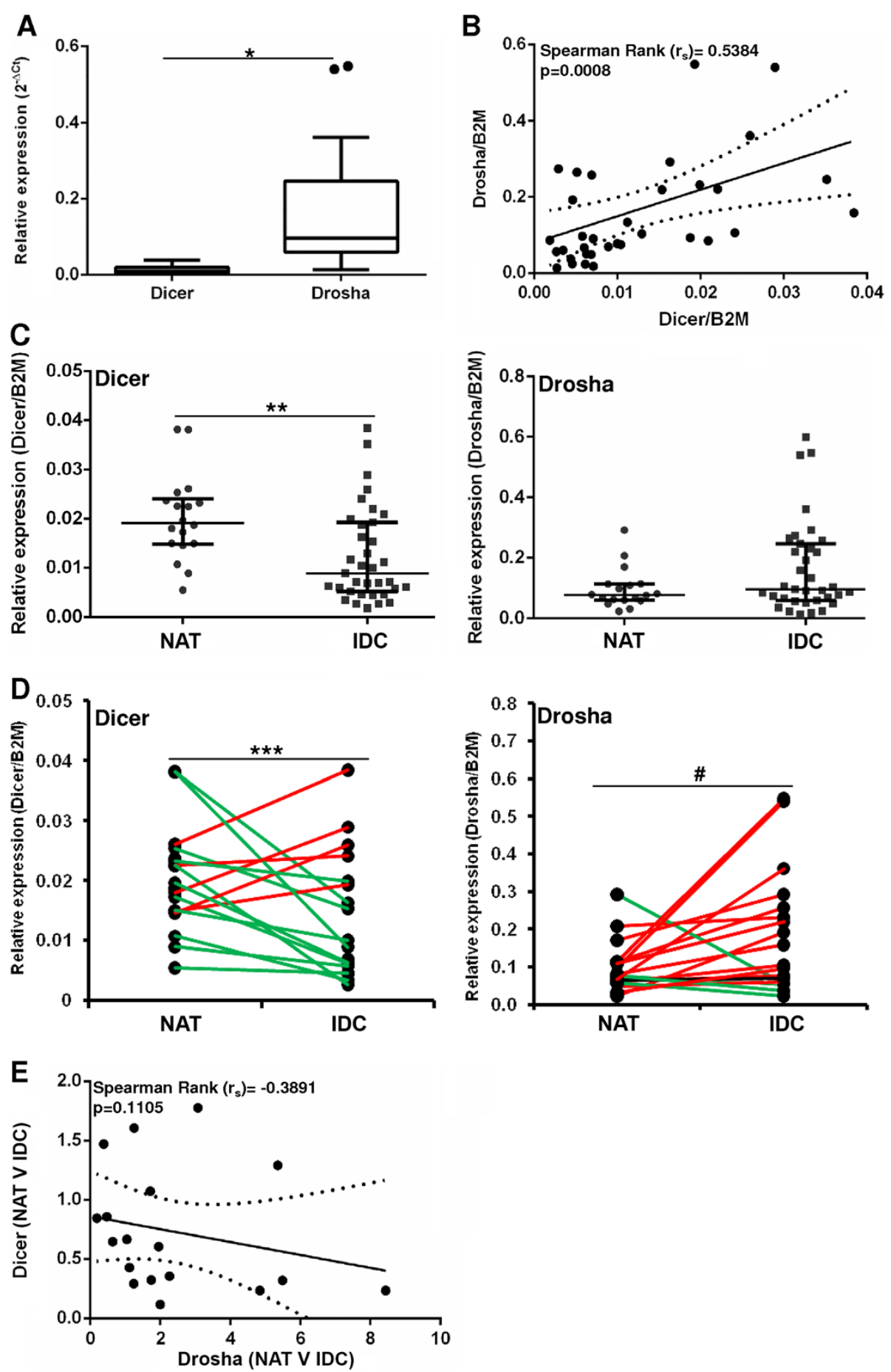

Figure 1 Dicer and Drosha expression in triple negative breast cancer. A) Relative quantification of Dicer and Drosha by real-time RT-PCR in tumour $(n=35)$ samples. B) The correlation between Dicer and Drosha expression levels. C) Relative quantification of Dicer and Drosha by real-time RT-PCR in all NAT $(n=18)$ and IDC $(n=35)$ samples. D) Relative quantification of Dicer and Drosha by real-time RT-PCR in matched NAT $(n=18)$ and IDC $(n=18)$ samples. E) Correlation between Dicer and Drosha fold change in IDC versus NAT samples. Results are shown as the relative normalised expression (target/ß2-Microglobulin) of the target $\left(2^{-\Delta C t}\right)$. Boxes (A) represent the median \pm interquartile range. Horizontal line (C) represents the median \pm interquartile range. Decreased and increased expression in tumour versus normal (D) is shown in green and red respectively. ${ }^{*} p<0.0001,{ }^{* *} p=0.0039,{ }^{* *} p=0.0432,{ }^{*} p=0.0235$. 
expression of Drosha was significantly higher $(\sim 11$ fold, $\mathrm{p}<0.0001$ ) than the expression of Dicer (Figure 1A). In addition, the expression of Dicer and Drosha were found to be highly correlated in tumours (Figure $1 \mathrm{~B}, \mathrm{r}_{\mathrm{s}}=0.5384$, $\mathrm{p}=0.0008$ ). This is consistent with the findings of Passon et al. and Dedes et al., who also found Dicer and Drosha expression to be correlated in breast cancer [21,23].

\section{Dicer is decreased while Drosha is increased in TNBC when compared to matched normal tissue}

There have only been two studies that have examined the relative expression of both Dicer and Drosha in TNBC in relation to the normal breast $[21,23]$. However, they compared their tumour specimens to a small number of unmatched normal breast tissues $(n=6, n=10)$ that were derived from reduction mammoplasty. Contrasting results were found with Passon et al. concluding that there was no significant difference in the expression of these two genes in the normal breast compared to TNBC [23] and Dedes et al., found a significant downregulation for Dicer only [21]. Given the heterogeneous nature of the breast, we examined Dicer and Drosha expression in TNBC compared to matched normal adjacent tissues (NAT). Initially, we examined all NAT $(n=18)$ compared to all tumours $(n=35)$ and found the expression of Dicer and Drosha was highly variable in both tissue types (Figure 1C). Dicer expression was found to be significantly reduced in tumour tissue compared to NAT in the unmatched analysis ( $\mathrm{p}=0.0039$ ), while no difference was observed for Drosha expression (Figure 1C). This is consistent with the results of Dedes et al. [21].

We next examined the expression of Dicer and Drosha in the matched NAT-tumour pairs $(n=18)$. Again, Dicer was found to be significantly reduced in $13 / 18$ (72\%) tumours compared to NAT (Figure 1D, $\mathrm{p}=0.0432$ ). In contrast, Drosha was significantly increased in 14/18 (78\%) tumours when compared to matched NAT (Figure 1D, $\mathrm{p}=0.0235)$. Given the contrasting results, we hypothesised that decreased Dicer expression may be compensating for increased Drosha expression in these tissues and examined whether the fold change in Dicer and Drosha expression in tumour versus NAT was correlated. We found no correlation between Dicer and Drosha fold induction in tumour compared to NAT (Figure 1E, $\mathrm{p}=0.1105$ ).

\section{Dicer and Drosha are not associated with clinical features of TNBC}

There are mixed reports regarding whether Dicer and Drosha are associated with disease progression in breast cancer $[18,19,21,22]$. However, the relationship of these genes to progression and other clinical features in the TNBC subtype has not been studied. We examined the relative expression of Dicer and Drosha in matched LN metastases to determine if there was a progressive loss in Dicer or gain in Drosha from normal to tumour to metastasis. We compared this to the expression of these genes in tumours that were $\mathrm{LN}$ negative. The fold change in the expression of Dicer and Drosha in tumour compared to NAT was similar in $\mathrm{LN}+$ and $\mathrm{LN}$ - tumours (compare IDC- vs NAT- with IDC + vs NAT+, Figure 2). The fold increase in Drosha expression when LN metastases were compared to their matched primary tumour (LN vs IDC+) was not different to the increase observed in tumour versus NAT (IDC + vs NAT+) (Figure 2B). In contrast, there was a significant increase in Dicer expression when LN metastases were compared to their matched primary tumour (LN vs IDC+, $\mathrm{p}=0.0202$, Figure 2A). This suggests that while there is a decrease in Dicer in the progression from normal to tumour, there is a subsequent increase following metastases to the lymph node. The

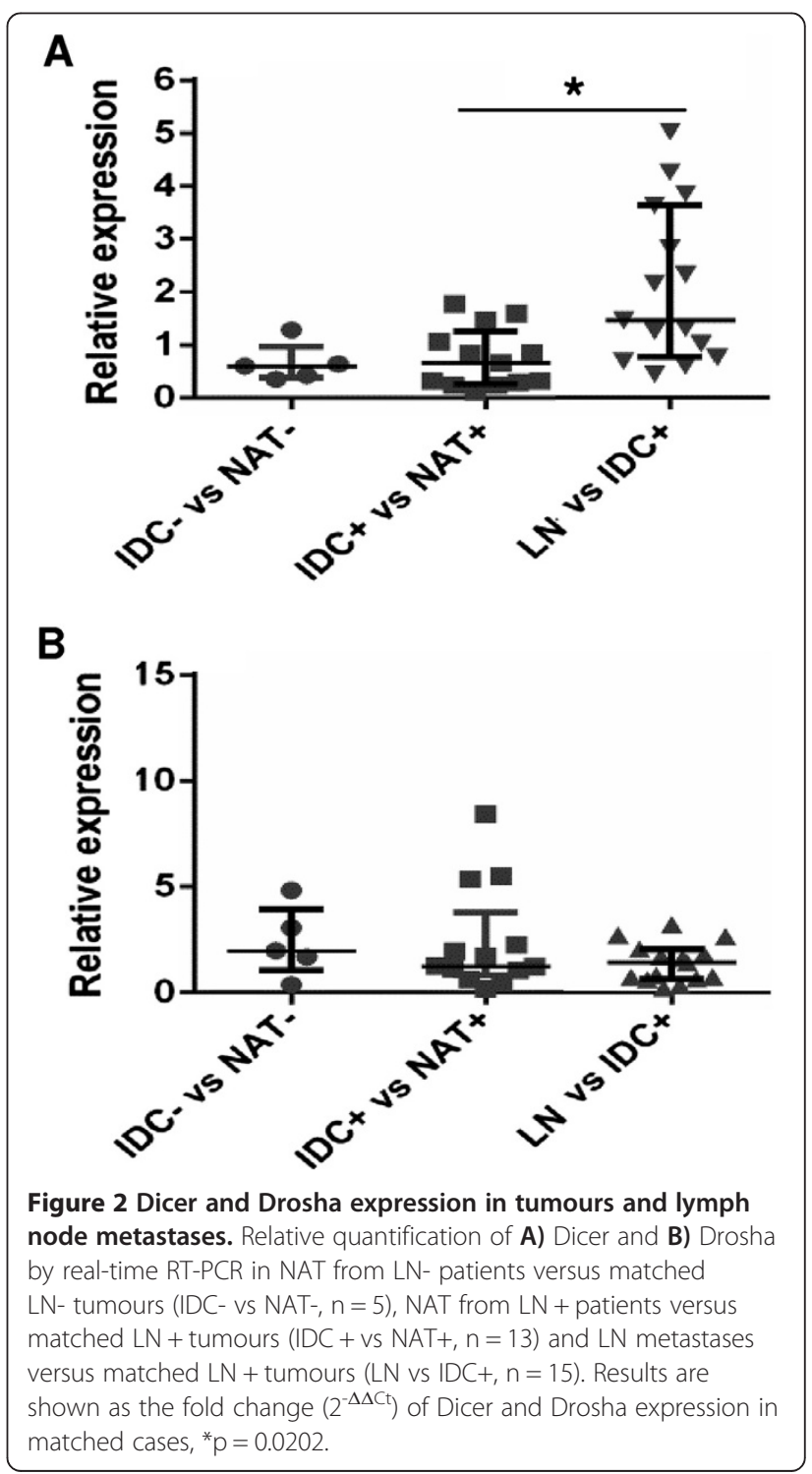


increase in Dicer expression in LN metastases was observed in 12/15 tumours analysed.

We examined whether the expression of Dicer or Drosha in tumours was associated with clinical features of breast cancer. We found no correlation of either Drosha or Dicer expression with age at diagnosis, tumour size or the number of positive lymph nodes (Table 1).

\section{Discussion}

Dicer and Drosha have been reported to be dysregulated in TNBC $[21,23]$. However, these studies used very few normal tissues in their analysis and the correlation with LN metastases was not examined. This study aimed to evaluate whether the relative expression of Dicer and Drosha was altered in TNBC and whether it was associated with clinical features and progression to LN metastases in this subtype.

Our results have shown that Drosha was expressed at significantly higher levels than Dicer in TNBC and that the expression of these two genes was highly correlated with one another, in agreement with the results of Passon et al. and Dedes et al. [21,23]. Decreased expression of Dicer has been noted in several cancers, while increased expression has been observed in ovarian, prostate and colorectal cancer [12-14]. We observed a significant decrease in Dicer expression in breast cancer when compared to matched NAT. The proportion of cases with decreased Dicer expression in this study $(72 \%)$ is similar to that previously reported by Passon et al. (61.3\%) and Dedes et al. (77.7\%) $[21,23]$. In contrast, we observed a significant increase in Drosha expression in $78 \%$ of the tumour tissues analysed when compared to matched NAT. This confirms previous findings that Drosha is increased in TNBC [23]. The relevance of increased Drosha expression and decreased Dicer expression in TNBC is not known at present. It is possible that Dicer expression becomes

Table 1 Correlation between Dicer and Drosha expression levels with clinical variables in triple negative breast cancer

\begin{tabular}{lcc}
\hline & Dicer & Drosha \\
\hline Age at diagnosis & & \\
$r_{s}^{*}$ & -0.1756 & -0.1240 \\
$p$-value & 0.3130 & 0.4778 \\
Tumour size & & \\
$r_{s}^{*}$ & 0.05331 & 0.1014 \\
$p$-value & 0.7610 & 0.5620 \\
No. of positive lymph nodes & & \\
$r_{s}^{*}$ & 0.08541 & 0.04540 \\
$p$-value & 0.6257 & 0.7957 \\
\hline${ }^{*}$ Values represent Spearman's rank correlation coefficient. &
\end{tabular}

*Values represent Spearman's rank correlation coefficient. decreased as a result of increased Drosha expression to limit miRNA biogenesis, thereby reducing miRNA function in the breast.

Reduced Dicer expression as well as over-expression has previously been reported to be associated with worse prognosis in breast and colorectal cancer respectively, indicating cancer specific differences in the prognostic value of this gene $[14,19]$. Although we did not have outcome data on the patients used in this study, we were able to examine whether Dicer and Drosha were differentially expressed in LN positive patients compared to LN negative patients and whether this expression was related to clinical features in the highly aggressive TNBC subtype. While Dicer was reduced in primary breast cancers of both LN positive and LN negative patients; unexpectedly, we found its expression significantly increased in LN metastases when compared to matched primary tumours. However, we saw no association of either Dicer or Drosha with clinical features including age at diagnosis, tumour size or the number of positive lymph nodes. This may be due to the small sample size used in this analysis, but TNBC represents a very specific proportion of all breast cancers and these specimens are difficult to obtain. This is the only study to date that has analysed Dicer and Drosha in TNBC samples compared to matched normal adjacent tissue and matched lymph node metastases.

A limitation of our study is that it was performed only on cDNA derived from FFPE tissues. Although FFPE tissues contain fragmented RNA, our real-time RT-PCR assays were designed with small amplicon sizes (Dicer$65 \mathrm{bp}$, Drosha- $66 \mathrm{bp}$ and $\beta 2$-Microglobulin- $75 \mathrm{bp}$ ) to circumvent the requirement for intact RNA. Additionally, random hexamers were incorporated in the reversetranscription procedure, which do not require the RNA to be intact, in contrast to reverse-transcription with oligo dT. Given the inconsistent correlations between these enzymes at the mRNA and protein level in the literature, and that the interpretation/quantification of Dicer and Drosha immunohistochemical staining is problematic, we did not perform immunohistochemical analyses on this cohort of tumours $[21,22]$. Although, the sample size used in this study is relatively small, the tumours are homogenous with regards to size, hormone receptor status and histological grade and this is the only study that has analysed matched TNBC cases and lymph node metastases.

\section{Conclusions}

This study has shown that Dicer and Drosha are dysregulated in TNBC and matched LN metastases. We have shown that Dicer is down-regulated, while Drosha is upregulated in primary breast cancers compared to NAT. There was no difference in Drosha expression in lymph 
node metastases when compared to the primary tumour, however, Dicer was significantly increased. This suggests that while there is a decrease in Dicer in the progression from NAT to tumour, there is a subsequent increase following metastases to the lymph node. The clinical relevance of this is under investigation.

\section{Additional file}

\section{Additional file 1: Table S1. Average and median Cts for}

B2-Microglobulin in NAT, IDC and LNs. Figure S1. The expression of $\beta 2$-Microglobulin in NAT, IDC and LNs. Values represent the median with interquartile ranges. No significant difference $(p>0.05)$ was observed between the sub-groups (Kruskal-Wallis rank test followed by a Dunn's Multiple Correction test).

\section{Abbreviations}

TNBC: Triple negative breast cancer; miRNA: microRNA; RT-PCR: Reverse transcription polymerase chain reaction; ER: Estrogen receptor;

PR: Progesterone receptor; HER2: Human epidermal growth factor receptor: LN: Lymph node; NAT: Normal adjacent tissue; IDC: Invasive ductal carcinoma; FFPE: Formalin fixed paraffin embedded; RNA: Ribonucleic acid; cDNA: complementary deoxyribonucleic acid.

\section{Competing interests}

The authors declare they have no competing interests.

\section{Authors' contributions}

KAK: study concept and design, carried out experiments, analysis and interpretation of data, drafting of the manuscript. SGB: patient collection, material support, manuscript revision. JFF: study design, obtained funding, critical revision of the manuscript for important intellectual content. RJS: study design, obtained funding, critical revision of the manuscript for important intellectual content. All authors read and approved the final manuscript.

\section{Acknowledgements}

The authors would like to thank Dr Ricardo Vilain for pathological review of all tumour and normal tissue specimens used in this analysis and Ms Tina Hope for assistance with archival specimens. This work was supported by funding from the National Breast Cancer Foundation. Dr Avery-Kiejda is supported by a Hunter Translational Cancer Research Unit Fellowship from the Cancer Institute NSW.

\section{Author details}

${ }^{1}$ Centre for Information-Based Medicine, Hunter Medical Research Institute, John Hunter Hospital, New Lambton Heights, NSW 2305, Australia. ${ }^{2}$ School of Biomedical Sciences and Pharmacy, Faculty of Health, University of Newcastle, Callaghan, NSW 2308, Australia. ${ }^{3}$ Hunter Area Pathology Service, John Hunter Hospital, New Lambton Heights, NSW 2305, Australia.

${ }^{4}$ Australian New Zealand Breast Cancer Trials Group and, Department of Surgical Oncology, Calvary Mater Newcastle Hospital, Waratah, NSW 2298, Australia. ${ }^{5}$ School of Medicine and Public Health, Faculty of Health, University of Newcastle, Callaghan, NSW 2308, Australia.

\section{Received: 5 August 2013 Accepted: 9 April 2014}

Published: 11 April 2014

\section{References}

1. Kamangar F, Dores GM, Anderson WF: Patterns of cancer incidence, mortality, and prevalence across five continents: defining priorities to reduce cancer disparities in different geographic regions of the world. J Clin Oncol 2006, 24(14):2137-2150.

2. Podo F, Buydens LM, Degani H, Hilhorst R, Klipp E, Gribbestad IS, Van Huffel S, van Laarhoven HW, Luts J, Monleon D, Postma GJ, Schneiderhan-Marra N, Santoro F, Wouters H, Russnes HG, Sorlie T, Tagliabue E, Borresen-Dale AL: Triple-negative breast cancer: present challenges and new perspectives. Mol Oncol 2010, 4(3):209-229.
3. Carey L, Winer E, Viale G, Cameron D, Gianni L: Triple-negative breast cancer: disease entity or title of convenience? Nat Rev Clin Oncol 2010, 7(12):683-692.

4. Jackson RJ, Standart N: How do microRNAs regulate gene expression? SCi STKE 2007, 2007:(367). re1.

5. Iorio MV, Ferracin M, Liu CG, Veronese A, Spizzo R, Sabbioni S, Magri E, Pedriali M, Fabbri M, Campiglio M, Menard S, Palazzo JP, Rosenberg A, Musiani P, Volinia S, Nenci I, Calin GA, Querzoli P, Negrini M, Croce CM: MicroRNA gene expression deregulation in human breast cancer. Cancer Res 2005, 65(16):7065-7070.

6. Foekens JA, Sieuwerts AM, Smid M, Look MP, de Weerd V, Boersma AW, Klijn JG, Wiemer EA, Martens JW: Four miRNAs associated with aggressiveness of lymph node-negative, estrogen receptor-positive human breast cancer. Proc Natl Acad Sci U S A 2008, 105(35):13021-13026.

7. Le Quesne JL, Jones J, Warren J, Dawson SJ, Ali R, Bardwell H, Blows F, Pharoah P, Caldas C: Biological and prognostic associations of miR-205 and let-7b in breast cancer revealed by in situ hybridisation analysis of micro-RNA expression in arrays of archival tumour tissue. J Pathol 2012, 227(3):306-314.

8. Rothe F, Ignatiadis M, Chaboteaux C, Haibe-Kains B, Kheddoumi N, Majjaj S, Badran B, Fayyad-Kazan H, Desmedt C, Harris AL, Piccart M, Sotiriou C: Global microRNA expression profiling identifies MiR-210 associated with tumor proliferation, invasion and poor clinical outcome in breast cancer. PLoS One 2011, 6(6):e20980

9. Volinia S, Galasso M, Sana ME, Wise TF, Palatini J, Huebner K, Croce CM: Breast cancer signatures for invasiveness and prognosis defined by deep sequencing of microRNA. Proc Natl Acad Sci U S A 2012, 109(8):3024-3029.

10. Yan LX, Huang XF, Shao Q, Huang MY, Deng L, Wu QL, Zeng YX, Shao JY: MicroRNA miR-21 overexpression in human breast cancer is associated with advanced clinical stage, lymph node metastasis and patient poor prognosis. RNA 2008, 14(11):2348-2360.

11. Yates LA, Norbury CJ, Gilbert RJ: The Long and Short of MicroRNA. Cell 2013, 153(3):516-519.

12. Chiosea S, Jelezcova E, Chandran U, Acquafondata M, McHale T, Sobol RW, Dhir R: Up-regulation of dicer, a component of the MicroRNA machinery, in prostate adenocarcinoma. Am J Pathol 2006, 169(5):1812-1820.

13. Chiosea S, Jelezcova E, Chandran U, Luo J, Mantha G, Sobol RW, Dacic S: Overexpression of Dicer in precursor lesions of lung adenocarcinoma. Cancer Res 2007, 67(5):2345-2350.

14. Faber C, Horst D, Hlubek F, Kirchner T: Overexpression of Dicer predicts poor survival in colorectal cancer. Eur J Cancer 2011, 47(9):1414-1419.

15. Karube Y, Tanaka H, Osada H, Tomida S, Tatematsu Y, Yanagisawa K, Yatabe Y, Takamizawa J, Miyoshi S, Mitsudomi T, Takahashi T: Reduced expression of Dicer associated with poor prognosis in lung cancer patients. Cancer Sci 2005, 96(2):111-115.

16. Merritt WM, Lin YG, Han LY, Kamat AA, Spannuth WA, Schmandt R, Urbauer D, Pennacchio LA, Cheng JF, Nick AM, Deavers MT, Mourad-Zeidan A, Wang H, Mueller P, Lenburg ME, Gray JW, Mok S, Birrer MJ, Lopez-Berestein G, Coleman RL, Bar-Eli M, Sood AK: Dicer, Drosha, and outcomes in patients with ovarian cancer. N Engl J Med 2008, 359(25):2641-2650.

17. Sugito $N$, Ishiguro $H$, Kuwabara $Y$, Kimura M, Mitsui A, Kurehara $H$, Ando $T$, Mori R, Takashima N, Ogawa R, Fujii Y: RNASEN regulates cell proliferation and affects survival in esophageal cancer patients. Clin Cancer Res 2006, 12(24):7322-7328.

18. Khoshnaw SM, Rakha EA, Abdel-Fatah T, Nolan CC, Hodi Z, Macmillan RD, Ellis IO, Green AR: The microRNA maturation regulator Drosha is an independent predictor of outcome in breast cancer patients. Breast Cancer Res Treat 2013, 137(1):139-153.

19. Khoshnaw SM, Rakha EA, Abdel-Fatah TM, Nolan CC, Hodi Z, Macmillan DR, Ellis IO, Green AR: Loss of Dicer expression is associated with breast cancer progression and recurrence. Breast Cancer Res Treat 2012, 135(2):403-413.

20. Yan M, Huang HY, Wang T, Wan Y, Cui SD, Liu ZZ, Fan QX: Dysregulated expression of dicer and drosha in breast cancer. Pathol Oncol Res 2012, 18(2):343-348.

21. Dedes KJ, Natrajan R, Lambros MB, Geyer FC, Lopez-Garcia MA, Savage K Jones RL, Reis-Filho JS: Down-regulation of the miRNA master regulators Drosha and Dicer is associated with specific subgroups of breast cancer. Eur J Cancer 2011, 47(1):138-150.

22. Grelier G, Voirin N, Ay AS, Cox DG, Chabaud S, Treilleux I, Leon-Goddard S, Rimokh R, Mikaelian I, Venoux C, Puisieux A, Lasset C, Moyret-Lalle C: 
Prognostic value of Dicer expression in human breast cancers and association with the mesenchymal phenotype. Br J Cancer 2009, 101(4):673-683.

23. Passon N, Gerometta A, Puppin C, Lavarone E, Puglisi F, Tell G, Di Loreto C, Damante G: Expression of Dicer and Drosha in triple-negative breast cancer. J Clin Pathol 2012, 65(4):320-326.

24. Avery-Kiejda KA, Braye SG, Mathe A, Forbes JF, Scott RJ: Decreased expression of key tumour suppressor microRNAs is associated with lymph node metastases in triple negative breast cancer. BMC Cancer 2014, 14(1):51.

25. Avery-Kiejda KA, Bowden NA, Croft AJ, Scurr LL, Kairupan CF, Ashton KA Talseth-Palmer BA, Rizos H, Zhang XD, Scott RJ, Hersey P: P53 in human melanoma fails to regulate target genes associated with apoptosis and the cell cycle and may contribute to proliferation. BMC Cancer 2011, 11(1):203

doi:10.1186/1471-2407-14-253

Cite this article as: Avery-Kiejda et al: The expression of Dicer and Drosha in matched normal tissues, tumours and lymph node metastases in triple negative breast cancer. BMC Cancer 2014 14:253.

\section{Submit your next manuscript to BioMed Central and take full advantage of:}

- Convenient online submission

- Thorough peer review

- No space constraints or color figure charges

- Immediate publication on acceptance

- Inclusion in PubMed, CAS, Scopus and Google Scholar

- Research which is freely available for redistribution 